\title{
The Thermal Behavior of Lyocell Fibers Containing Bis(trimethylsilyl)acetylene
}

\author{
Igor Makarov $^{1, *(\mathbb{D})}$, Markel Vinogradov ${ }^{1} \mathbb{D}$, Maria Mironova ${ }^{1, * \mathbb{D}}$, Georgy Shandryuk ${ }^{1}$, Yaroslav Golubev ${ }^{2}$ \\ and Anna Berkovich ${ }^{2}$
}

Citation: Makarov, I.; Vinogradov, M.; Mironova, M.; Shandryuk, G.; Golubev, Y.; Berkovich, A. The Thermal Behavior of Lyocell Fibers Containing Bis(trimethylsilyl)acetylene. Polymers 2021, 13, 537. https:// doi.org/10.3390/polym13040537

Academic Editor: Thang Quyet Tran

Received: 21 January 2021

Accepted: 8 February 2021

Published: 11 February 2021

Publisher's Note: MDPI stays neutral with regard to jurisdictional claims in published maps and institutional affiliations.

Copyright: (c) 2021 by the authors. Licensee MDPI, Basel, Switzerland. This article is an open access article distributed under the terms and conditions of the Creative Commons Attribution (CC BY) license (https:// creativecommons.org/licenses/by/ $4.0 /)$.
1 A.V. Topchiev Institute of Petrochemical Synthesis, Russian Academy of Sciences, 29 Leninsky prospect, 119991 Moscow, Russia; vin1989@ips.ac.ru (M.V.); gosha@ips.ac.ru (G.S.)

2 Chemical Department, M.V. Lomonosov Moscow State University, 1 Leninskiye Gory, 119991 Moscow, Russia; GolubevYV@vms.chem.msu.ru (Y.G.); annber@vms.chem.msu.ru (A.B.)

* Correspondence: makarov@ips.ac.ru (I.M.); mvmironova@ips.ac.ru (M.M.); Tel.: +74-956-475-927 (ext. 233) (M.M.)

\begin{abstract}
This study focuses on the preparation of carbon fiber precursors from solutions of cellulose in $N$-methylmorpholine- $N$-oxide with the addition of bis(trimethylsilyl)acetylene, studying their structural features and evaluating thermal behavior. The introduction of a silicon-containing additive into cellulose leads to an increase in the carbon yield during carbonization of composite precursors. The type of the observed peaks on the differential scanning calorimetry (DSC) curves cardinally changes from endo peaks intrinsic for cellulose fibers to the combination of endo and exo peaks for composite fibers. For the first time, coefficient of thermal expansion (CTE) values were obtained for Lyocell fibers and composite fibers with bis(trimethylsilyl)acetylene (BTMSA). The study of the dependence of linear dimensions of the heat treatment fibers on temperature made it possible to determine the relation between thermal expansion coefficients of carbonized fibers and thermogravimetric curves, as well as to reveal the relationship between fiber shrinkage and BTMSA bis(trimethylsilyl)acetylene content. Carbon fibers from composite precursors are obtained at a processing temperature of $1200^{\circ} \mathrm{C}$. A study of the structure of carbon fibers by X-ray diffraction, Raman spectroscopy, and transmission electron microscopy made it possible to determine the amorphous structure of the fibers obtained.
\end{abstract}

Keywords: cellulose; bis(trimethylsilyl)acetylene; lyocell fibers; thermal properties; coefficient of thermal expansion

\section{Introduction}

Carbon fibers (CFs), as an important class of heat-resistant fibers [1], have been intensively studied due to their excellent properties, such as high strength, heat resistance, low density, and chemical stability [2-4]. The main consumers of CFs are the aerospace industry, the automotive industry, sports equipment, and medicine [5-7].

The production of cellulose-based carbon materials is a current task, despite the fact that high-strength carbon fibers (CFs) are produced on an industrial scale from precursors based on polyacrylonitrile and pitch [8]. The relevance of the problem lies in obtaining CFs not only with the required mechanical characteristics, but also with a necessary coefficient of thermal expansion (CTE), which is known to be closely related to the structure of such fibers [9]. An important task remaining is a solution to the problem of replacing petroleum products with renewable plant sources of polymers that are processed into CFs. The importance of CTE values is related to the performance properties of the resulting composite materials where carbon fibers are used as a functional additive. Close values of the CTE of the matrix and the filler exclude the formation of defects, and as a consequence, give the best (stable) mechanical characteristics with a change in the temperature of the composite material [10,11]. 
The correct choice of a type of precursor and a process of its heat treatment allows for a necessary structure to be formed, and this directly affects CTE values of carbon fibers. Pradere and Sauder [12] reported that the largest values of the CTE in a longitudinal direction and the smallest in a transverse direction were observed for pitch-based carbon fibers (unoriented samples). The formation of an anisotropic structure in the sample leads to a change to opposite values.

Unlike polyacrylonitrile (PAN) precursors, during carbonization and further graphitization of cellulose fibers the interplanar spacing $d_{002}$ and the mutual arrangement of crystalline layers (strips of CF) are similar to graphite [13]. Consequently, there will be differences in the CTE values of carbon fibers obtained from such precursors.

Due to the specific structure of cellulose, the range of its direct solvents is limited [14]. Therefore, at the present moment, cellulose fibers, including technical yarns (cord), which are used as precursors of $\mathrm{CF}$, are produced on an industrial scale in the viscose and $\mathrm{N}$ methylmorpholine- $N$-oxide (NMMO) processes only [15]. If the first process is dominated by the volume of fibers produced, the second is characterized by smaller amounts of harmful emissions and higher energy efficiency [16].

According to the accepted classification of the international committee BISFA (International Bureau of Standardization of Man-Made Fibres (Brussels, Belgium)), fibers formed from cellulose solutions in NMMO received the general name Lyocell [17].

A decrease in the water content of NMMO increases its dissolving capacity with respect to cellulose. Using the direct solvent $\mathrm{NMMO}$ with water content of about $8 \%$ makes it possible to obtain Lyocell fibers from concentrated cellulose solutions (up to 18\%) [18]. The use of NMMO with a low water content is associated with high melting points of NMMO and obtaining solutions [19]. This imposes restrictions on the possible ways of processing solutions into fibers. Therefore, the dry-wet jet method of spinning fibers from cellulose solutions in NMMO is the main one used [20]. Water or aqueous NMMO solutions are often used as a precipitant [21].

The maximum possible carbon yield obtained during pyrolysis of cellulose does not exceed $44.4 \mathrm{wt} \%$ [22]; however, in reality, these values rarely exceed $30 \%$ and depend on pretreatment and thermolysis regimes [23]. An accumulated experience of processing cellulosic precursors into carbon fibers has shown that it is impossible to obtain high-quality CFs and increase carbon yield without the flame retardants and pyrolysis catalysts, which are able to influence the course of the thermal reaction used [24-27]. Production of carbon fibers from cellulosic precursors using ammonium compounds became a trend. Without concentrating on disadvantages of using such flame retardants and pyrolysis catalysts, we note that the use of silicon-containing compounds is proposed as an alternative. There are two main ways of using these compounds: impregnating the fibers with their solutions [28,29] and introducing them into dope as an additive [30].

In our previous work [31-34], advantages of the second method were revealed in comparison to fiber impregnation. It was also found that the introduction of organosilicon compounds into the cellulose matrix makes it possible to achieve a better distribution of the additive in the volume of cellulose fibers, to increase the yield on carbon, and to obtain composite carbon-silicon carbide composite fibers. The thermal behavior of the composite precursors is correlated with their structure and the chemical nature of the additive. Namely, the switch from tetraethoxysilane (TEOS) with a high C/O ratio to vinyltriethoxysilane (VTEOS) that has in its structure $\mathrm{Si}-\mathrm{C}$ and double bonds leads to reducing the activation energy of pyrolysis and decreasing the carbon yield.

The use of oxygen-free silicon-containing compounds is likely to reduce the mass loss during pyrolysis, where carbon loss is known to be accompanied by the formation of volatile $\mathrm{CO}$ and $\mathrm{CO}_{2}$. Therefore, the task of this work was to obtain composite precursors based on cellulose and bis(trimethylsilyl)acetylene through solid-phase solutions in $\mathrm{NMMO}$, and to study their structure and thermal behavior, as well as to determine the chemical composition and structure of the resulting carbon fibers. 


\section{Materials and Methods}

\subsection{Materials}

Sulfate powder cellulose with degree of polymerization DP $=600$, a moisture content of $7-8 \%$, and a mass content in the dry residue of alpha cellulose of $94 \%$ was provided by Baikal Pulp and Paper Mill (Baykalsk, Russia). The silicon-containing additives (bis(trimethylsilyl)acetylene (BTMSA) (ID 24851275)) were obtained from Sigma-Aldrich (St. Louis, MO, USA). Direct solvent of cellulose $\mathrm{N}$-methylmorpholine- $\mathrm{N}$-oxide (NMMO) with $T_{m}=120{ }^{\circ} \mathrm{C}\left(\mathrm{H}_{2} \mathrm{O}<10 \%\right)$ was supplied by Demochem (Shanghai, China). Solutions containing $18 \%$ cellulose with and without BTMSA in NMMO were prepared through a solid-phase activation method from mixtures of cellulose/BTMSA with content: 0, 5, and $10 \mathrm{wt} \%$ BTMSA (further in the text the designation of fiber samples is Si-0, Si-5, and Si-10, respectively) [35]. Propyl gallate ( $0.5 \mathrm{wt} \%)$ from Sigma-Aldrich was used to suppress thermo-oxidative degradation of the solvent.

\subsection{Fiber Spinning}

The fibers were formed by the dry-wet jet method on a Rheoscope 1000 capillary viscometer (CEAST, Italy) equipped with a fiber winding system (capillary diameter, $\mathrm{d}$, $1 \mathrm{~mm}$; length, $1,40 \mathrm{~mm} ; 1 / \mathrm{d}=40$ ). The size of the air gap between the capillary and the aqueous precipitation bath is $10 \mathrm{~cm}$. After the precipitation bath, the fibers were further washed with water until NMMO was completely removed. At the final stage, the fibers were dried at ambient conditions in a free state.

\subsection{Structure Characterization}

The structure of cellulose and composite fibers was investigated by X-ray diffractometry using a Rigaku Rotaflex-RC (Rigaku Corporation, Tokyo, Japan) unit equipped with a rotating copper anode (30 kV-100 mA source operating mode, characteristic wavelength of $\mathrm{CuK}_{\alpha}$ radiation $\lambda=0.15418 \mathrm{~nm}$ ), a horizontal D-Max/B goniometer, and a scintillation detector. A nickel filter was used to absorb $\mathrm{CuK}_{\beta}$ radiation. X-ray experiments were performed at room conditions in a "Bragg-Brentano" transmission mode geometry in the continuous $\theta-2 \theta$ scanning mode (angular range of $2 \theta, 2.5-50^{\circ}$; scanning step, $0.04^{\circ}$ ). To obtain the diffractograms of the fibers, parallel bundles of their fragments (around 100 pieces) were used in vertical or horizontal directions relative to the goniometer axis.

The Raman scattering measurements were performed in a Raman spectrometer (Horiba LabRAM HR Evolution, Kyoto, Japan) equipped with a $532 \mathrm{~nm}$ laser excitation wavelength at room temperature. The Raman spectrometer was operated in the continuous scanning mode.

\subsection{Mechanical Properties}

Specimens of composite fibers with BTMSA were tested using an Instron universal tensile machine (Instron, model 1122, Norwood, MA, USA) supplied with pneumatic clamps. The fiber diameters were measured with an optical microscope (Biomed-6PO, Moscow, Russia). An extension rate of $10 \mathrm{~mm} \mathrm{~min}^{-1}$ and a working length of $10 \mathrm{~mm}$ were used for all specimens.

\subsection{Scanning Electron Microscopy (SEM)}

Micrographs of the surface and cross-section of cellulose and composite fibers were obtained on a scanning electron microscope (JSM U-3, JEOL, Tokyo, Japan). Cellulose fibers, unlike carbon fibers derived from them, are less brittle. That is why, in order to obtain SEM micrographs, cellulosic precursors were previously placed in an epoxy rubber matrix, and then after they were cured, a cross-section was made using a microtome cutter. The cross-sections of the carbon fibers were obtained by a simple mechanical action.

Structures, morphologies, and elemental compositions of fibers produced at $1200^{\circ} \mathrm{C}$ were studied on an Osiris transmission electron microscope (FEI, Hillsboro, OR, USA) at an accelerating voltage of $200 \mathrm{kV}$ in transmission electron microscopy, high-resolution 
electron microscopy, and scanning-transmission electron microscopy modes (using an energy-dispersive X-ray spectrometer).

\subsection{Thermal Properties}

The thermal behavior was examined on a thermogravimetric analyzer and differential scanning calorimeter combined instrument (TGA/DSC1, Mettler Toledo, Greifensee, Switzerland). The measurements were carried out in the temperature range from $30^{\circ} \mathrm{C}$ to $1000{ }^{\circ} \mathrm{C}$ at a heating rate of $10{ }^{\circ} \mathrm{C} \mathrm{min}^{-1}$. The flow rate of the argon reaction gas was

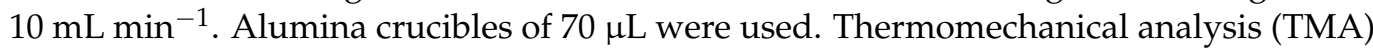
was performed on a TMA 402 F1 Hyperion instrument (Netzsch, Selb, Germany) (SiC furnace, $\mathrm{Al}_{2} \mathrm{O}_{3}$ holder). The measurement mode was tension. The fibers of the precursor sample were fixed in clamps with a total sample diameter of $1 \mathrm{~mm}$. The distance between the clamping plates was $20 \mathrm{~mm}$ for the first measurement and $10 \mathrm{~mm}$ for the next one. To prepare tensioned specimens, an alignment jig was used to fix the distance between corundum clamps of $20 \mathrm{~mm}$ and $10 \mathrm{~mm}$, respectively. At the first stage, the samples were heated in an $\mathrm{Ar}$ atmosphere from $25^{\circ} \mathrm{C}$ to $500{ }^{\circ} \mathrm{C}$ at a rate of $10^{\circ} \mathrm{C} \mathrm{min}-1$ with a total flow of $70 \mathrm{~mL} \mathrm{~min}{ }^{-1}$. The applied tensile force during heating was constant and equal to $100 \mathrm{mN}$. At the second stage, the samples were reheated in an Ar atmosphere from $25^{\circ} \mathrm{C}$ to $1200{ }^{\circ} \mathrm{C}$ at a rate of $10^{\circ} \mathrm{C} \mathrm{min}-1$ with a total flow of $70 \mathrm{~mL} \mathrm{~min}^{-1}$. The applied tensile force during heating was constant and equal to $50 \mathrm{mN}$.

\section{Results}

\subsection{Structure of Cellulose and Composite Fibers}

Introduction of silyl-substituted acetylene into cellulose solutions does not practically affect the rheological behavior of the filled solutions; i.e., it did not require a change to the spinning procedure. Therefore, just as in the case of cellulosic solutions, the solutions with BTMSA were formed by the dry-jet wet method. The diffractograms of the fibers obtained are shown in Figure 1.

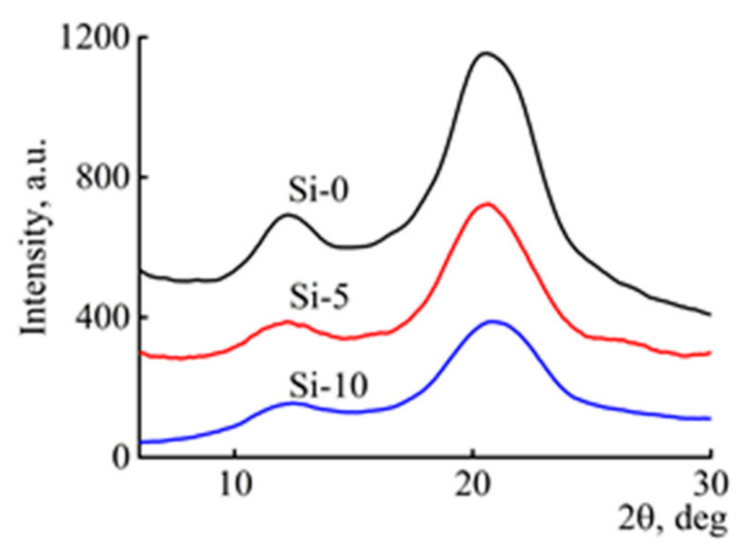

Figure 1. Equatorial diffractograms of Si-0, Si-5, and Si-10 fibers.

In the process of cellulose solution preparation and regeneration, the system of hydrogen bond was broken, resulting in the destruction of the cellulose I structure, which made the crystal structure of cellulose I turn into cellulose II. The introduction of BTMSA into the cellulose matrix does not lead to a change in the angular position of the basal reflections of cellulose $2 \theta=12.3^{\circ}$ and $20.6^{\circ}$, which corresponds to the interplanar distance of $3.61 \AA$ and $2.19 \AA$, respectively, and belongs to the cellulose polymorphic form II [36]. An increase in the content of BTMSA in the fibers results in a change in the intensity of the main reflections and the cellulose crystallinity. 


\subsection{Morphology of Cellulose and Composite Fibers}

The SEM images of cellulose and composite fiber surfaces and cross-sections are shown in Figure 2.

For all spun fibers, a circular shape and regular size were observed along the fiber axis, consistent with the cross-section morphology given by Rous [37]. The surface of the fibers is smooth and without visible anomalies. Pictures ( $b$ and d) show the cross-sections of the cellulose and composite fibers, respectively. Voids or defects are missing in the crosssections. The cellulose and composite fibers show a relatively dense structure. The absence of delamination indicates acceptable adhesion of the components during coagulation. This suggests that the process of coagulation of cellulose and silicon-filled solutions proceeds according to the same mechanism.
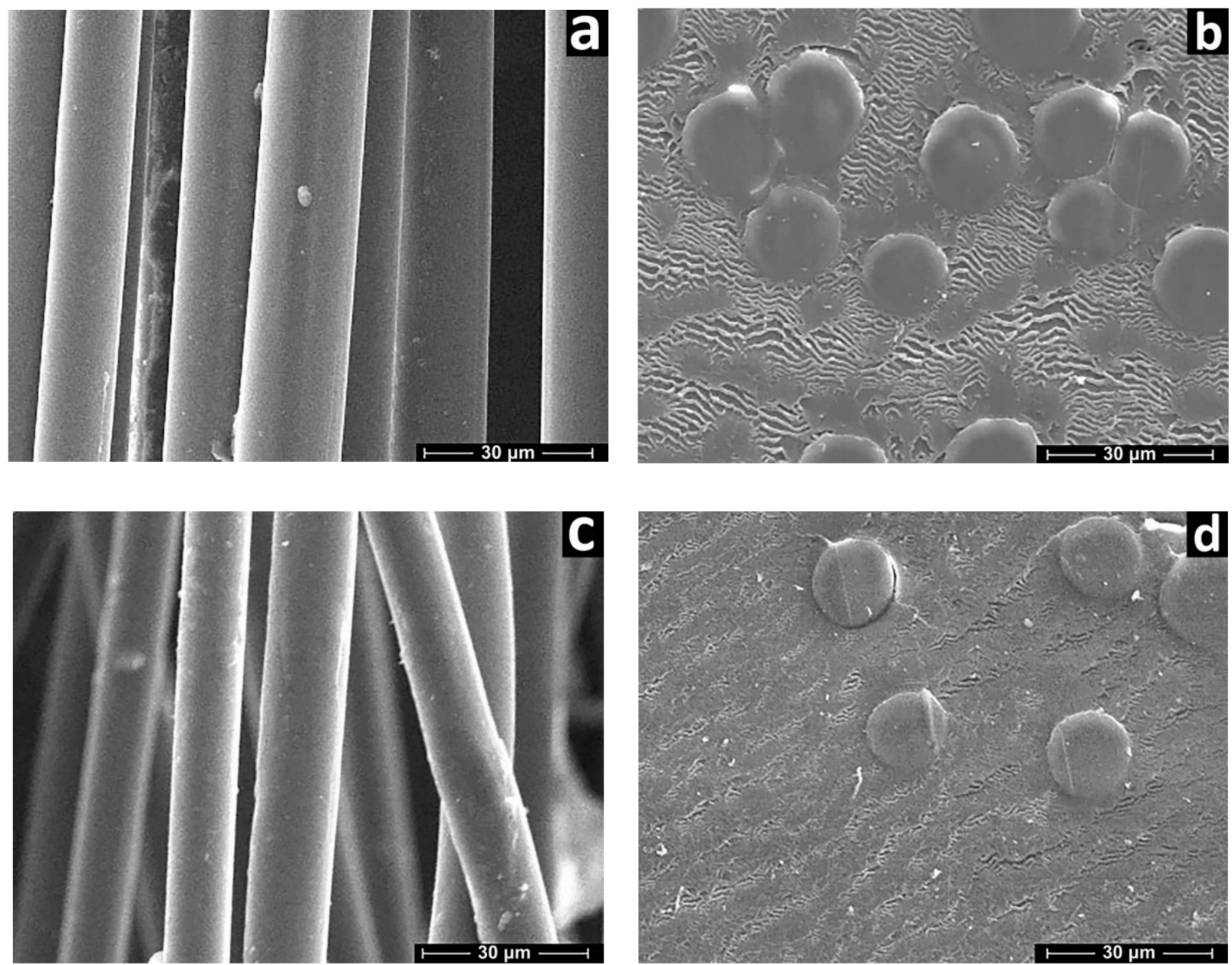

Figure 2. Microphotographs of Si-0 (a,b) and Si-5 (c,d) fibers (a,c-surface; b,d-cross-section).

\subsection{Mechanical Properties}

Structural changes are caused by a composite additive and its effect on the mechanical characteristics of the fibers (Table 1).

Table 1. Mechanical properties of cellulose and composite fibers.

\begin{tabular}{ccccc}
\hline Sample & Diameter $(\boldsymbol{\mu m})$ & Tensile Strength $\mathbf{( M P a )}$ & Elongation (\%) & Modulus (GPa) \\
\hline Si-0 & $17.0 \pm 2.8$ & $590 \pm 22$ & $11.0 \pm 0.8$ & $11.0 \pm 0.9$ \\
Si-5 & $12.0 \pm 2.3$ & $565 \pm 34$ & $7.0 \pm 2.1$ & $14.8 \pm 2.1$ \\
Si-10 & $12.5 \pm 1.5$ & $515 \pm 43$ & $7.0 \pm 1.2$ & $13.4 \pm 2.3$ \\
\hline
\end{tabular}


Composite fibers compared with cellulose are characterized by lower values of strength and elongation at break. The fibers containing BTMSA show a decreased tensile strength, especially when the BTMSA content is $10 \mathrm{wt} \%$. The modified fibers also show lower values of elongation at break than those of unmodified fibers. For Si- 5 or Si-10, elongation is $7 \%$, respectively. On the other hand, all the modified fibers show a higher modulus in comparison with unmodified fibers. The highest values of modulus are observed for Si-5. In general, the changes observed in the values of mechanical characteristics are not critical and it is possible to use the obtained composite fibers as precursors for CFs.

\subsection{Thermal Behavior}

It is known that the thermal behavior of fibers depends on both the structure of the precursor [38,39] and the chemical nature of the additive used [40]. Therefore, to determine the effect of BTMSA on pyrolytic mechanisms and the carbon yield, the thermal behavior of the fibers was studied by differential scanning calorimetry (DSC) and thermal gravimetric analysis (TGA) (Figures 3 and 4).

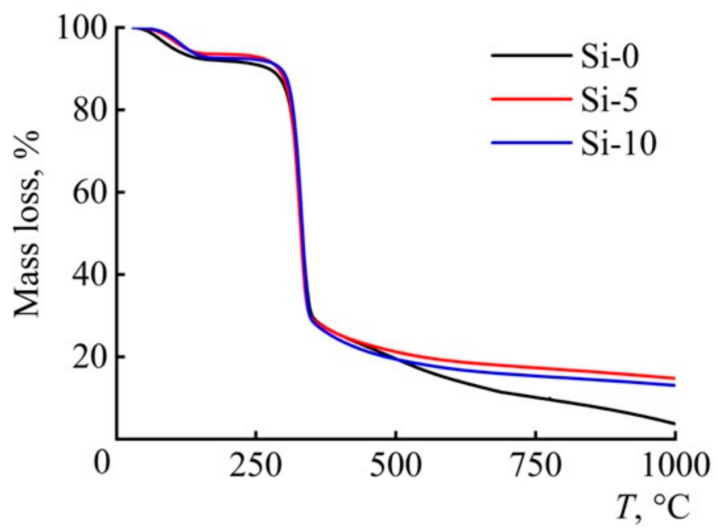

(a)

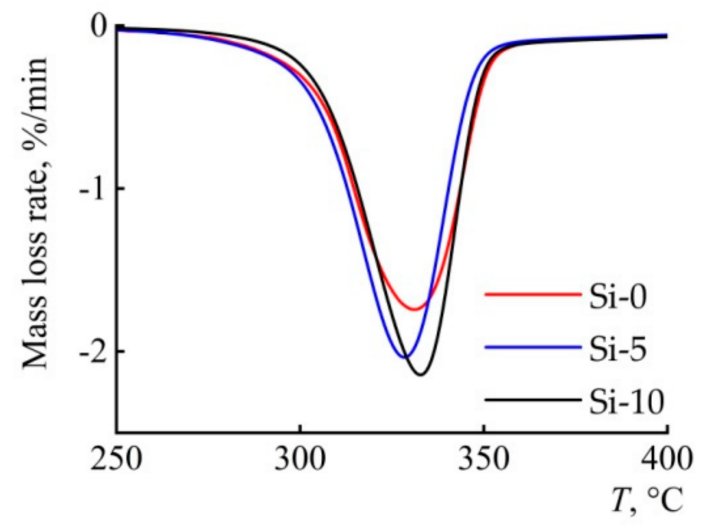

(b)

Figure 3. Thermogravimetric curves (TG) (a) and differential curves of the mass loss rate DTG (b) for Si-0, Si-5, and Si-10 fibers. Atmosphere: argon $10 \mathrm{~mL} \mathrm{~min}{ }^{-1}$. Linear heating rate of $10^{\circ} \mathrm{C} \mathrm{min}^{-1}$.

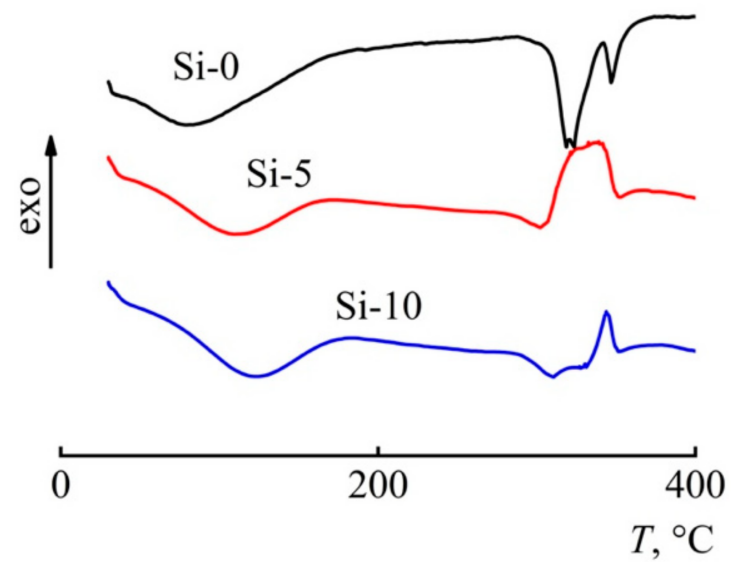

Figure 4. DSC curves for Si-0, Si-5, and Si-10 fibers. Atmosphere: argon $10 \mathrm{~mL} \mathrm{~min}^{-1}$. Linear heating rate of $10^{\circ} \mathrm{C} \mathrm{min}{ }^{-1}$.

The course of thermogravimetric curves for cellulose and composite fibers has a traditional appearance and includes areas for release of the adsorbed moisture, dehydration, and depolymerization and a high-temperature region with lower rates of mass loss [41]. The addition of $5 \%$ BTMSA into cellulose leads to a significant increase in the values of 
the carbon yield. A further increase in the additive content up to $10 \%$ does not provide an increase in the carbon yield. Table 2 presents the main results of the TG studies.

Table 2. TG and DTG data for cellulose and composite fibers.

\begin{tabular}{|c|c|c|c|c|}
\hline Sample & $T_{\max }\left({ }^{\circ} \mathrm{C}\right)$ & $\mathrm{DTG}_{\max }\left(\% \min ^{-1}\right)$ & $T_{\text {onset }}\left({ }^{\circ} \mathrm{C}\right)$ & $E_{a}^{1}\left(\mathrm{~kJ} \mathrm{~mol}^{-1}\right)$ \\
\hline $\mathrm{Si}-0$ & 331 & -1.74 & 281 & 234 \\
\hline Si-5 & 328 & -2.03 & 279 & 162 \\
\hline Si-10 & 332 & -2.14 & 279 & 172 \\
\hline
\end{tabular}

${ }^{1} E a$ was calculated using the Broido formula [42].

In the study, the single heating rate kinetic method was applied. Generally, this method is not recommended by the International Confederation for Thermal Analysis and Calorimetry Kinetic Committee [43-45] — but as an express method for evaluating $E_{a}$, it is convenient and allows one to get the first ideas about the activation energy of the pyrolysis process. Comparing onset temperatures of degradation revealed that cellulose fibers had the same thermal stability as compared with the composite fibers. At the same time, the activation energy of pyrolysis for composite fibers is reduced by $30 \%$. With increasing concentration of BTMSA, an increase in the maximum rate of mass loss is observed.

Along with the TGA studies, DSC curves for cellulose and composite fibers were obtained. Endo-effects that appeared in the process of pyrolysis of cellulose fibers are converted into a combination of endo- and exo-effects. The mechanism for changing the nature of the peaks is not yet completely clear; however, it can be assumed that the nature of the additive contributes to the process along with structural factors.

The difference in weight loss for fibers containing BTMSA is formed during the thermal decomposition stage and is fixed at a temperature of about $500{ }^{\circ} \mathrm{C}$ (Figure 5). TMA of fibers preliminarily subjected to heating to $500{ }^{\circ} \mathrm{C}$ in an argon atmosphere showed a difference in CTE of fibers in the temperature range of $25-400{ }^{\circ} \mathrm{C}$ and absolute values of expansion of the samples along the drawing direction (Table 3). The largest value corresponds to the sample containing 5\% BTMSA, and the smallest value to that of the cellulose fibers. The increase in thermal expansion can be explained by the appearance of additional regions of ordering, which is in agreement with the pattern of thermogravimetric curves. An increase in BTMSA content reduces fiber shrinkage, which can be observed by the divergence of thermomechanical curves in the temperature range $620-1200{ }^{\circ} \mathrm{C}$. The observed phenomenon is possibly related to the melting of $\mathrm{SiO}_{2}$ silicates and other products formed as a result of joint heating of cellulose and BTMSA.

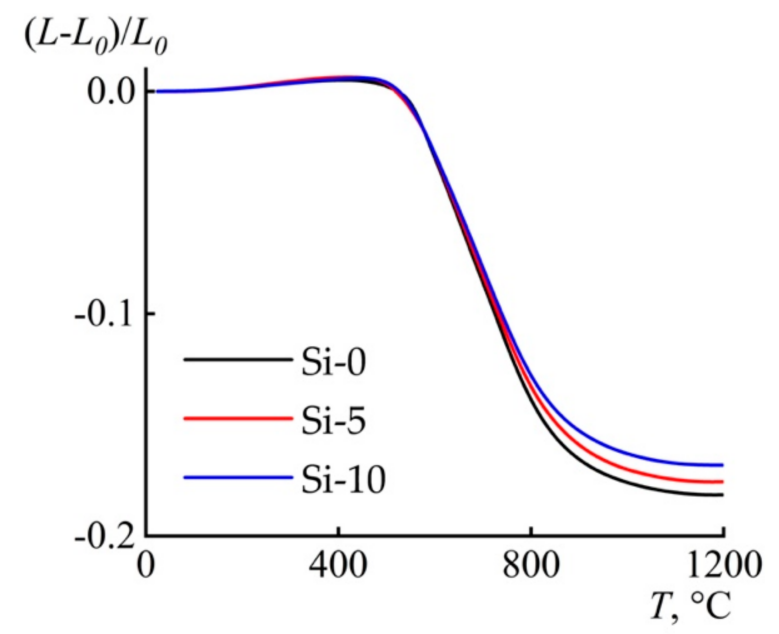

Figure 5. Thermomechanical analysis (TMA) curve for of Si-0, Si-5, and Si-10. Atmosphere: argon $70 \mathrm{~mL} \mathrm{~min}{ }^{-1}$. Linear heating rate of $10^{\circ} \mathrm{C} \mathrm{min}^{-1}$. $L$-current sample size; $L_{0}$-initial sample size. 
Table 3. TMA data for cellulose and composite fibers.

\begin{tabular}{|c|c|c|c|}
\hline Sample & $\begin{array}{c}\left(L-L_{0}\right)^{1} \times 10^{3} / L_{0} \\
25-400{ }^{\circ} \mathrm{C} \\
(\text { step I) }\end{array}$ & $\begin{array}{c}\mathrm{CTE} \times 10^{6}, \\
\text { (average from } \\
30^{\circ} \mathrm{C} \text { to } 400^{\circ} \mathrm{C} \text { ) }\end{array}$ & $\begin{array}{c}\left(L-L_{0}\right) \times 10^{3} / L_{0} \\
25-1200{ }^{\circ} \mathrm{C} \\
\text { (step II) }\end{array}$ \\
\hline Si-0 & 5.02 & 13.50 & -181.45 \\
\hline Si-5 & 6.31 & 16.99 & -175.61 \\
\hline Si-10 & 5.58 & 14.98 & -168.09 \\
\hline
\end{tabular}

${ }^{1} L$-current sample size; $L_{0}$-initial sample size.

\subsection{Morphology and Structure of Carbonized Fibers}

Practice shows that the morphology of carbonized fibers directly depends on the morphology of precursors [46]. That is why a round cross-section, few physical defects, and fine denier of precursors give hope for similar characteristics in carbon fibers. After carbonization of composite precursors, the average fiber diameter decreases from $12 \mu \mathrm{m}$ to $6 \mu \mathrm{m}$ (Figure 6).
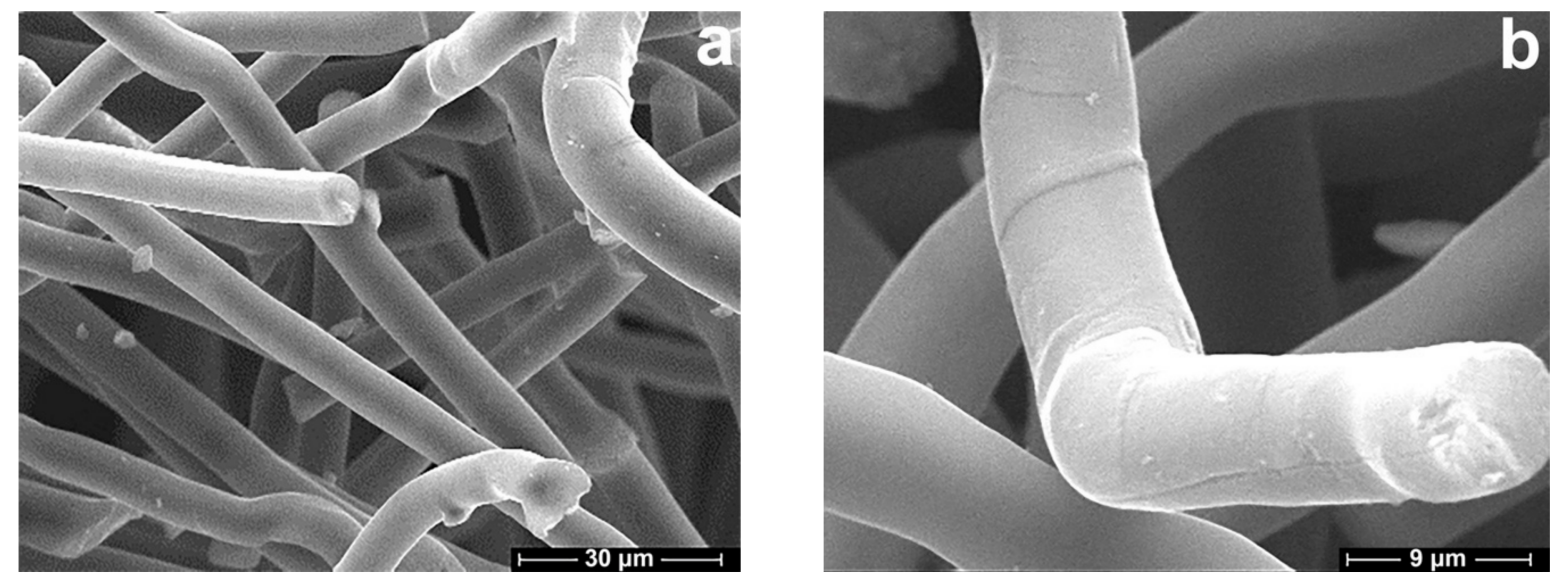

Figure 6. SEM micrographs of the surface (a) and cross-section (b) morphology of carbon fibers, derived from Si-5 fibers at $1200^{\circ} \mathrm{C}$.

From a comparison of the morphology of precursors (Figure 2) and carbonized fibers, it can be concluded that the main geometric characteristics of the fibers are preserved. The surface of the fibers is smooth with no observable defects. The thickness of the fibers is maintained along the fiber axis.

It is possible to trace the supramolecular organization of carbon in the obtained CFs by using the TEM method (Figure 7).
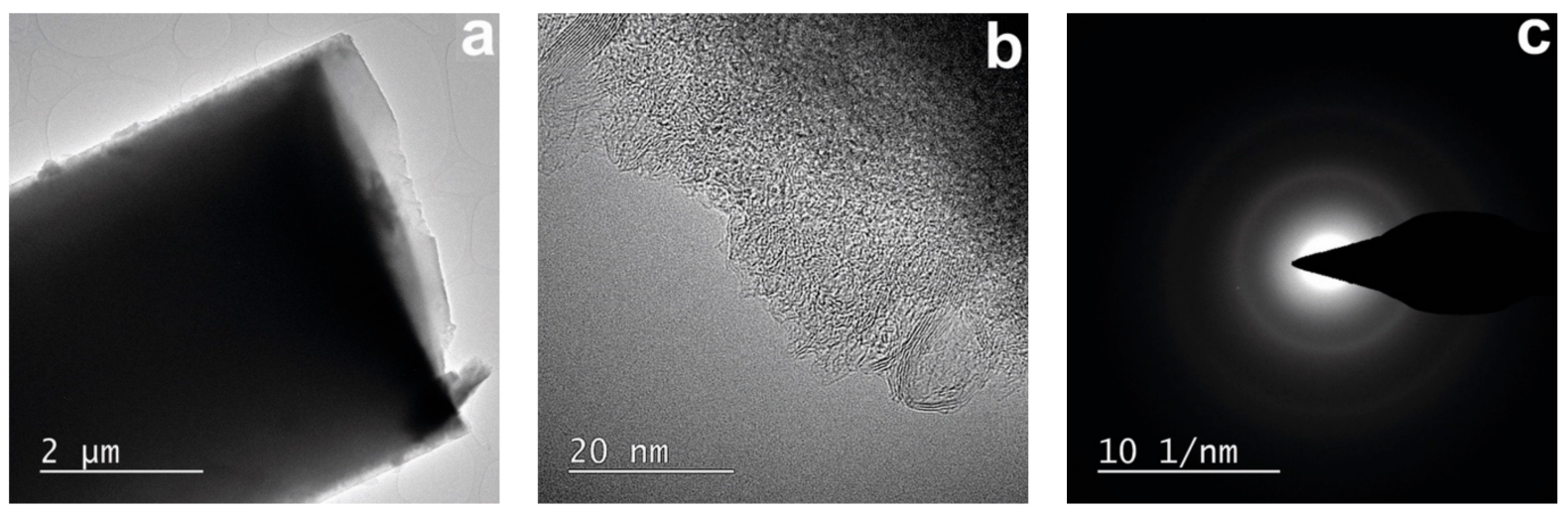

Figure 7. TEM images $(\mathbf{a}, \mathbf{b})$ of carbon fibers obtained from precursors Si-10 by heat treatment up to $1200{ }^{\circ} \mathrm{C}$ and selected area electron diffraction (SAED) patterns of amorphous area of carbon fibers (CFs) (c). 
The surface area and the cross-section of the fibers (Figure 7a,b) are "transparent" for the electron beam, which makes it possible to scan the fibers. Comparison of the fibers' surface and cross-section morphology revealed a predominantly isotropic structure for the sample, which corresponds to diffractograms with diffuse rings (Figure 7c). A study of the cross-section with a higher magnification revealed two types of structures (Figure $7 \mathrm{~b}$ ). The first type is composed of randomly "intertwined" carbon layers, and the second is ordered domains consisting of parallel layers. The distance between the layers of the domains $\left(\mathrm{d}_{002}\right)$ varies over a wide range, though not reaching values characteristic of graphite (0.3354) [47]

The diffractograms of the fibers (Figure 8) revealed peaks in the range of $2 \theta=22.5^{\circ}$ (002) and $43.9^{\circ}(100)$. The $\mathrm{d}_{002}$ values obtained by the TEM method and calculated using the Bragg formula have a common size range. The broad peak (002) observed in the diffraction pattern can be attributed to the amorphous carbon phase [48].

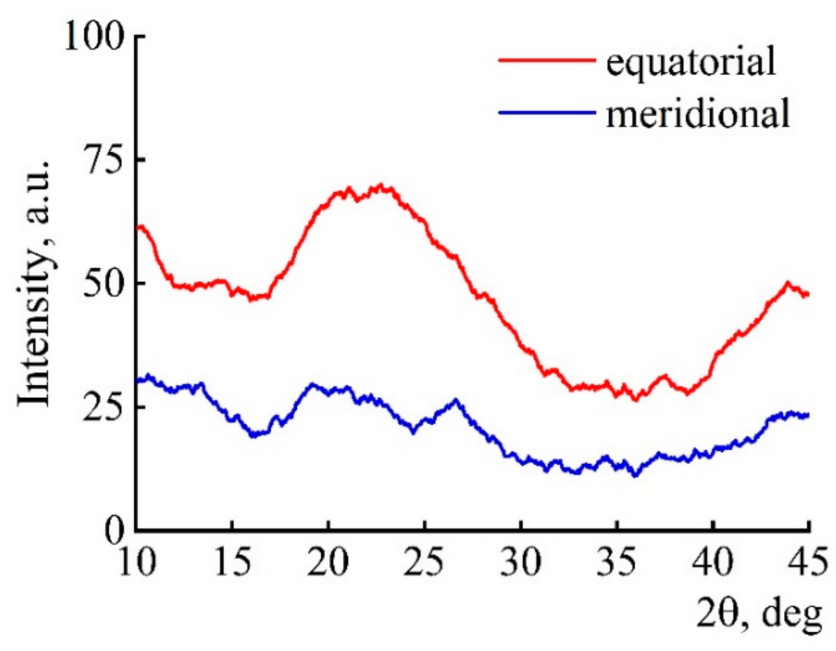

Figure 8. X-ray diffraction patterns of composite fibers (Si-10).

The Raman spectra (Figure 9) exhibit a broad D band at $1335 \mathrm{~cm}^{-1}$ and a $\mathrm{G}$ band at $1585 \mathrm{~cm}^{-1}$. In other words, the sample contains both disordered (D band) and crystalline carbon $G$ bands. As in the case of $X$-ray results, the low intensity of the $G$ bands (at the $D$ band level) suggests domination of a disordered (very close to amorphous) structure in the obtained CFs [49-51].

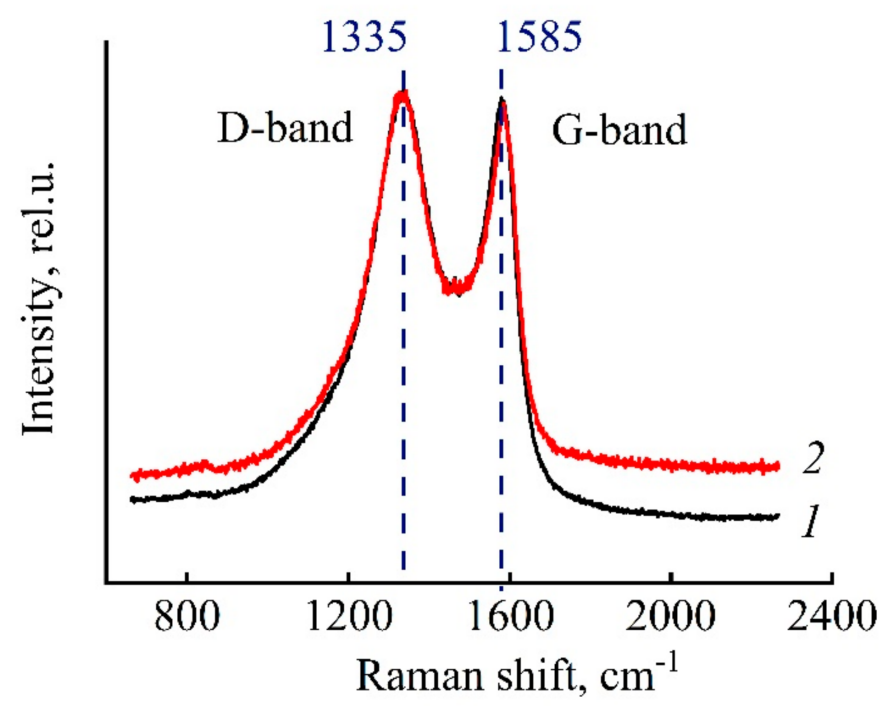

Figure 9. Raman spectra of carbon fibers obtained by heat treatment up to $1200{ }^{\circ} \mathrm{C}$ from the Si-0 precursor (1) and the composite (Si-10) precursor (2). 
Thus, the introduction of BTMSA into the cellulosic matrix influences an order in composite precursor carbon fibers, and its presence enables the ability to increase the carbon yield during their heat treatment. As a result, the obtained CF has mainly an amorphous carbon matrix structure with a small number of ordered regions.

The chemical composition and distribution of elements in CF were determined by the EDS (energy-dispersive spectroscopy) method (Figure 10).
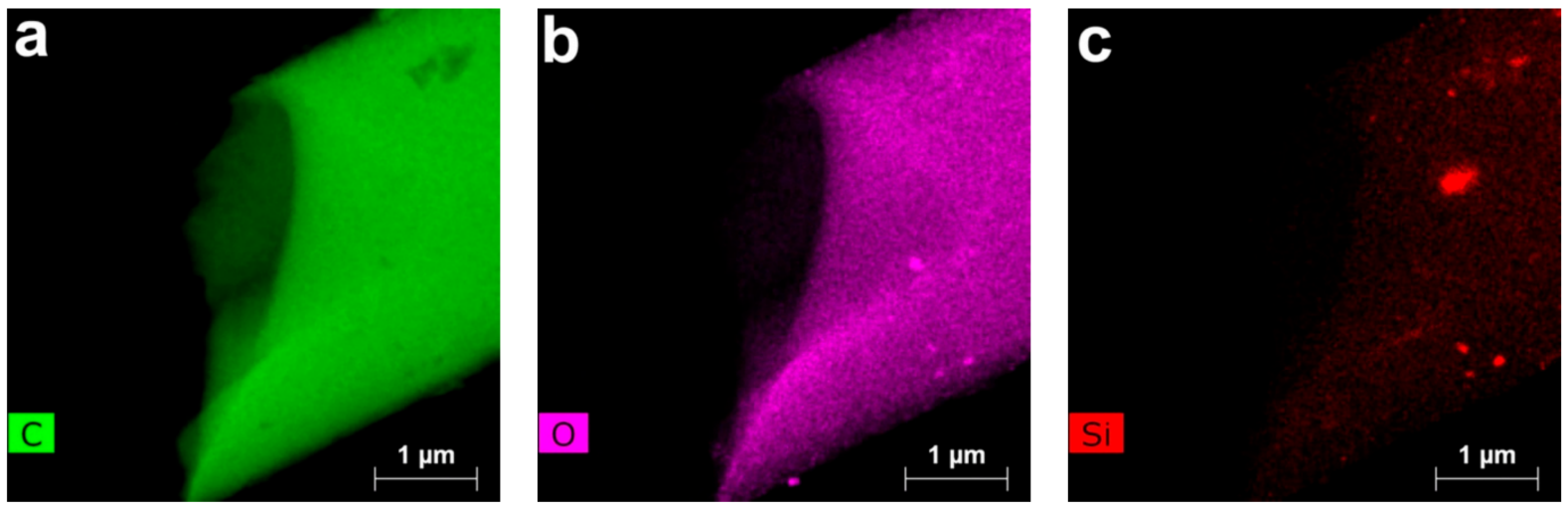

Figure 10. EDS elements mapping of $\mathrm{C}(\mathbf{a}), \mathrm{O}(\mathbf{b})$, and $\mathrm{Si}(\mathbf{c})$ for carbon fibers obtained from precursors of $\mathrm{Si}-10$ by heat treatment up to $1200{ }^{\circ} \mathrm{C}$.

Unlike carbon and oxygen, which have a uniform distribution, only the local silicon clusters can be detected on the silicon distribution map; the average size of clusters can reach hundreds of nanometers.

The average mass of silicon in carbon fibers obtained from composite fibers with BTMSA does not exceed tenths of a percent of the total sample mass, which is significantly less compared with the results obtained for precursors with additions of TEOS and VTEOS [31-34]. It is likely that, in the process of carbonization of precursors with BTMSA, the silicon-containing additive is volatilized, which in turn should also affect the structure of the CF.

\section{Conclusions}

In this work, we prepared composite precursors based on cellulose and BTMSA, studied their structure and properties, and received carbon fibers from them. The addition of BTMSA into the cellulose matrix at the stage of solution preparation makes it possible to obtain composite precursors with a good distribution of silicon in the volume of the polymer. Composite precursors are characterized by a transformation in the structural order with an increase in the content of BTMSA. The mechanical properties of composite fibers obtained are slightly different from those of cellulose fibers, which allows them to be processed into carbon fibers. For all composite fibers, the activation energy of pyrolysis is less than that for cellulose fibers. At the same time, the reaction itself starts first for samples with BTMSA and later for cellulose; i.e., BTMSA reduces the decomposition temperature of cellulose. The type of observed peaks on the DSC curves cardinally changes from the endo peaks intrinsic for cellulose fibers to the combination of endo and exo peaks for composite fibers. This may indicate a number of chemical processes occurring during the decomposition of samples that lead to an increase in the carbon yield at high temperatures. The effect of BTMSA addition on cellulose fibers is also to reduce fiber shrinkage at temperatures above $600{ }^{\circ} \mathrm{C}$. The structure of the obtained fibers differs from the one inherent for high-strength CF, and as a result it is expected to have perspective CTE values. 
Author Contributions: Conceptualization, I.M. and M.M.; methodology, I.M., G.S. and A.B.; investigation, I.M., M.V., G.S. and Y.G.; data analysis, I.M., M.M. and A.B.; writing-original draft preparation, I.M., M.V. and Y.G.; writing-review and editing, I.M. and M.M.; supervision, I.M. All authors have read and agreed to the published version of the manuscript.

Funding: This work was carried out within the State Program of TIPS RAS.

Institutional Review Board Statement: Not applicable.

Informed Consent Statement: Not applicable.

Data Availability Statement: The data presented in this study are available on request from the corresponding author.

Acknowledgments: The authors are grateful to V.G. Kulichikhin for a helpful discussion of the study results.

Conflicts of Interest: The authors declare no conflict of interest.

\section{References}

1. Konkin, A.A. Carbon and Other Heat-Resistant Fibrous Materials; Khimiya: Moscow, Russia, 1974.

2. Nashchokin, A.V.; Malakho, A.P.; Galiguzov, A.A.; Kulakov, V.V.; Seleznev, A.N.; Avdeev, V.V. Dependence of the mechanical properties, morphology, and structural characteristics of different types of carbon fibers on treatment temperature. Fibre Chem. 2012, 44, 180-185. [CrossRef]

3. Lian, F.; Liu, J.; Xue, Y.; Ma, Z.; Liang, J. The demonstration of a dense and stable circumferential layer in the subsurface of polyacrylonitrile fibers for carbon fibers. Fibers Polym. 2013, 14, 243-249. [CrossRef]

4. Wang, Y.-Y.; Wu, G.-P.; Li, R.-M.; Li, X.-L.; Lu, C.-X. Fracture mechanisms of polyacrylonitrile-based high-strength type carbon fibers. Fibers Polym. 2014, 15, 2541-2543. [CrossRef]

5. Varshavsky, V.Y. Carbon Fibers, 2nd ed.; FGUP PIK VINITI: Moscow, Russia, 2007.

6. Karacan, I.; Erdogan, G. The influence of thermal stabilization stage on the molecular structure of polyacrylonitrile fibers prior to the carbonization stage. Fibers Polym. 2012, 13, 295-302. [CrossRef]

7. Saklakova, E.V.; Astashkina, O.V.; Medvedeva, N.G.; Kuzikova, I.L.; Lysenko, A.A. Antibacterial Properties of Carbon Fibers Containing Metal Nano- and Microparticles. Fibre Chem. 2015, 47, 324-328. [CrossRef]

8. Hu, X.C.; Zhang, H.H.; Shao, H.; Zhang, T.; Guo, L. Process for preparing precursor fiber of cellulose base carbon fiber. Patent CN 1587457A, 3 February 2004.

9. Makarov, I.S.; Golova, L.K.; Bondarenko, G.N.; Skvortsov, I.Y.; Berkovich, A.K.; Bermeshev, M.V.; Mironova, M.V. Carbon-SiliconCarbide Fibers Prepared from Solid Solutions of Cellulose in N-Methylmorpholine-N-Oxide with Added Tetraethoxysilane. Fibre Chem. 2017, 49, 231-236. [CrossRef]

10. Kulkarni, R.; Ochoa, O. Transverse and Longitudinal CTE Measurements of Carbon Fibers and their Impact on Interfacial Residual Stresses in Composites. J. Compos. Mater. 2006, 40, 733-754. [CrossRef]

11. Zhang, Y.-H.; Wu, G.-H. Interface and thermal expansion of carbon fiber reinforced aluminum matrix composites. Trans. Nonferrous Met. Soc. China 2010, 20, 2148-2151. [CrossRef]

12. Pradere, C.; Sauder, C. Transverse and longitudinal coefficient of thermal expansion of carbon fibers at high temperatures (300-2500K). Carbon 2008, 46, 1874-1884. [CrossRef]

13. Belenkov, E.A. Formation of graphite structure in carbon fiber. Chelyabinsk Phys. Math. J. 1998, 6, 42-53.

14. Bochek, A.M. Effect of hydrogen bonding on cellulose solubility in aqueous and nonaqueous solvents. Russ. J. Appl. Chem. 2003, 76, 1711-1719. [CrossRef]

15. Golova, L.K.; Borodina, O.E.; Kuznetsova, L.K.; Lyubova, T.A.; Krylova, T.B. The solid-phase MMO process. Fibre Chem. 2000, 32, 243-251.

16. Ciechanska, D.; Wesolowska, E.; Wawro, D. An introduction to cellulosic fibres. In Handbook of Textile Fibre Structure; Eichhorn, S.J., Hearle, J.W.S., Jaffe, M., Kikutani, T., Eds.; Woodhead Publishing: Cambridge, UK, 2009; Volume 2, pp. 3-61.

17. Burger, C.; Maron, R.; Michels, C.; Mick, K.P. New types of cellulose materials obtained by an alternative spinning method. Fibre Chem. 1996, 28, 22-27. [CrossRef]

18. Golova, L.K.; Borodina, O.E.; Rudinskaya, G.Y.; Papkov, S.P. Optical properties and structure of highly concentrated solutions of cellulose in N-methylmorpholine N-oxide. Fibre Chem. 2001, 33, 140-144. [CrossRef]

19. Golova, L.K.; Kulichikhin, V.G.; Papkov, S.P. Mechanism of dissolution of cellulose in non-aqueous dissolving systems. Rev. Polym. Sci. U.S.S.R. 1986, 28, 1995-2011.

20. Golova, L.K. Processing of cellulose via highly concentrated "solid solutions". Fibre Chem. 1996, 28, 5-16. [CrossRef]

21. Golova, L.K. New cellulose fiber lyocell. Russ. J. Gen. Chem. 2002, XLVI, 49-57.

22. Sporl, J.M.; Beyer, R.; Abels, F.; Cwik, T.; Muller, A.; Hermanutz, F.; Buchmeister, M.R. Cellulose-derived carbon fibers with improved carbon yield and mechanical properties. Macromol. Mater. Eng. 2017, 302, 1-10. [CrossRef]

23. Huang, X. Fabrication and properties of carbon fibers. Materials 2009, 2, 2369-2403. [CrossRef] 
24. Chernenko, D.N. Development and research of technological process of obtaining carbon fabrics from hydrated cellulose fibers. Bachelor's Thesis, Research Institute of Structural Materials based on graphite "NIIgraphit", Moscow, Russia, 2015.

25. Sporl, J.M.; Ota, A.; Son, S.; Massonne, K.; Hermanutz, F.; Buchmeiser, M.R. Carbon fibers prepared from ionic liquid-derived cellulose precursors. Mater. Today Commun. 2016, 7, 1-10. [CrossRef]

26. Kazakov, M.E.; Trushnikov, A.M.; Yunitskaya, M.L. The Method of Obtaining Carbon Fiber Material. Patent RF 2045472, 10 October 1995.

27. Olri, P.; Plezantene, E.; Louison, S.; Paye, R. Carbonization of Cellulosic Fibrous Materials in the Presence of an Organosilicon Compound. Patent RF 2256013, 10 July 2005.

28. Trushnikov, A.M.; Kazakov, M.E.; Gridina, Y.F.; Vazheva, L.D.; Borisova, L.K. The Method of Obtaining Carbon Fiber Material. Patent RF 2047674, 10 November 1995.

29. Olri, P.; Louison, S.; Kazakov, M.E.; Trushnikov, A.M. The Method of Obtaining Carbon Fiber Material. Patent RF 2258773, 20 August 2005.

30. Wizon, I.; Robertson, J.A. Continuous filament ceramic fibers via the viscose process. J. Polym. Sci. Part. C 1967, 19, 267-281. [CrossRef]

31. Makarov, I.S.; Golova, L.K.; Kuznetsova, L.K.; Bondarenko, G.N.; Skvortsov, I.Y.; Mironova, M.V.; Bermeshev, M.V. Composite fibers based on cellulose and tetraethoxysilane: Preparation, structure and properties. Fibre Chem. 2017, 49, 101-107. [CrossRef]

32. Golova, L.K.; Makarov, I.S.; Bondarenko, G.N.; Mironova, M.V.; Berkovich, A.K.; Shandryuk, G.A.; Vinogradov, M.I.; Bermeshev, M.V.; Kulichikhin, V.G. Composite Fibers Based on Cellulose and Vinyltriethoxysilane as Precursors of Carbon Materials. Polym. Sci. Ser. B. 2020, 62, 152-162. [CrossRef]

33. Makarov, I.S.; Golova, L.K.; Mironova, M.V.; Vinogradov, M.I.; Kulichikhin, V.G. Composite fibres based on cellulose and vinyltriethoxysilane: Preparation, properties and carbonization. Mat. Sci. Eng. 2018, 347, 012032. [CrossRef]

34. Makarov, I.S.; Golova, L.K.; Mironova, M.V.; Vinogradov, M.I.; Bermeshev, M.V.; Berkovich, A.K.; Kulichikhin, V.G. Structural and morphological features of carbon-silicon-carbide fibers based on cellulose and triethoxyvinylsilane. Fibre Chem. 2018, $50,79-84$.

35. Golova, L.K.; Romanov, V.V.; Lunina, O.B.; Platonov, V.A.; Papkov, S.P.; Khorozova, O.D.; Yakshin, V.V.; Belasheva, T.P.; Sokira, A.N. Method for Producing a Solution for Spinning Fibers. Patent RF 1645308, 30 April 1991.

36. Blackburn, R. Biodegradable and Sustainable Fibres; Woodhead Publishing: Cambridge, UK, 2005.

37. Abu-Rous, M.; Ingolic, E.; Schuster, K.C. Visualisation of the nano-structure of Tencel ${ }^{\circledR}$ (Lyocell) and other cellulosics as an approach to explaining functional and wellness properties in textiles. Lenzing. Ber. 2006, 85, 31-37.

38. Hideno, A. Comparison of the Thermal degradation properties of crystalline and amorphous cellulose, as well as treated lignocellulosic biomass. BioResources 2016, 11, 6309-6319. [CrossRef]

39. Kulichikhin, V.G.; Skvortsov, I.Y.; Mironova, M.V.; Ozerin, A.N.; Kurkin, T.S.; Berkovich, A.K.; Frenkin, E.I.; Malkin, A.Y. From polyacrylonitrile, its solutions, and filaments to carbon fibers II. Spinning PAN-precursors and their thermal treatment. Adv. Polym. Technol. 2018, 37, 1099-1113. [CrossRef]

40. Niekraszewicz, B.; Czarnecki, P. Modified cellulose fibers prepared by the N-Methylmorpholine-N-oxide (NMMO) process. J. Appl. Polym. Sci. 2002, 86, 907-916. [CrossRef]

41. Makarov, I.S.; Golova, L.K.; Vinogradov, M.I.; Levin, I.S.; Shandryuk, G.A.; Arkharova, N.A.; Golubev, Y.V.; Berkovich, A.K.; Eremin, T.V.; Obraztsova, E.D. The effect of alcohol precipitants on structural and morphological features and thermal properties of lyocell fibers. Fibers 2020, 8, 43. [CrossRef]

42. Broido, A. A simple, sensitive graphical method of treating thermogravimetric analysis data. J. Polym. Sci. Part. A-2 1969, 7, 1761-1773. [CrossRef]

43. Brown, M.E.; Maciejewski, M.; Vyazovkin, S.; Nomen, R.; Sempere, J.; Burnham, A.; Opfermann, J.; Strey, R.; Anderson, H.L.; Kemmler, A.; et al. Computational aspects of kinetic analysis: Part A: The ICTAC kinetics project-data, methods and results. Thermochim. Acta 2000, 355, 125-143. [CrossRef]

44. Vyazovkin, S.; Burnham, A.K.; Criado, J.M.; Pérez-Maqueda, L.A.; Popescu, C.; Sbirrazzuoli, N. ICTAC kinetics committee recommendations for performing kinetic computations on thermal analysis data. Thermochim. Acta 2011, 520, 1-19.

45. Tanaka, H. The theory and practice of thermoanalytical kinetics of solid-state reactions. J. Therm. Anal. Calorim. 2005, 80, 795-797. [CrossRef]

46. Bacon, R. Carbon fibers from rayon precursors. In Chemistry and Physics of Carbon; Walker, P.L., Jr., Thrower, P.A., Eds.; Marcel Dekker: New York, NY, USA, 1974; Volume 9, p. 1.

47. Belenkov, E.A.; Iakovlev, D.V. Peculiarities of the form analysis of profiles X-Ray diffraction lines for carbon materials. Part II. Relation of the profiles form and crystals distribution on the sizes. Bull. Chelyabinsk Sci. Cent. Ural Branch RAS 2001, 2, 37-45.

48. Cho, S.Y.; Yun, Y.S.; Jin, H.J. Carbon nanofibers prepared by the carbonization of self-assembled cellulose nanocrystals. Macromol. Res. 2014, 22, 753-756. [CrossRef]

49. Ferrari, A.C.; Robertson, J. Resonant raman spectroscopy of disordered, amorphous, and diamondlike carbon. Phys. Rev. B Condens. Matter. 2001, 64, 075414. [CrossRef]

50. Ferrari, A.C.; Robertson, J. Interpretation of Raman spectra of disordered and amorphous carbon. Phys. Rev. B Condens. Matter. 2000, 61, 14095-14107.

51. Dychalska, A.; Popielarski, P.; Franków, W.; Fabisiak, K.; Paprocki, K.; Szybowicz, M. Study of CVD diamond layers with amorphous carbon admixture by Raman scattering spectroscopy. Mater. Sci. 2015, 33, 799-805. [CrossRef] 